\title{
A regional geomagnetic field model over Southern Africa derived with harmonic splines from Swarm satellite and ground-based data recorded between 2014 and 2019
}

Emmanuel Nahayo ${ }^{1 *}$ and Monika Korte ${ }^{2}$

\begin{abstract}
A regional harmonic spline geomagnetic main field model, Southern Africa Core Field Model (SACFM-3), is derived from Swarm satellite and ground-based data for the southern African region, in the eastern part of the South Atlantic Anomaly (SAA) where the field intensity continues to decrease. Using SACFM-3 and the global CHAOS-6- $\times 9$ model, a detailed study was conducted to shed light on the high spatial and temporal geomagnetic field variations over Southern Africa between 2014 and 2019. The results show a steady decrease of the radial component $Z$ in almost the entire region. In 2019, its rate of decrease in the western part of the region has reached high values, 76 nT/year and $78 \mathrm{nT} /$ year at Tsumeb and Keetmanshoop magnetic observatories, respectively. For some areas in the western part of the region the radial component $Z$ and field intensity $F$ have decreased in strength, from 1.0 to $1.3 \%$ and from 0.9 to 1.2\%, respectively, between the epochs 2014.5 and 2019.5. There is a noticeable decrease of the field intensity from the south-western coast of South Africa expanding towards the north and eastern regions. The results show that the SAA area is continuing to grow in the region. Abrupt changes in the linear secular variation in 2016 and 2017 are confirmed in the region using ground-based data, and the $X$ component shows an abrupt change in the secular variation in 2018 at four magnetic observatories (Hermanus, Hartebeesthoek, Tsumeb and Keetmanshoop) that needs further investigation. The regional model SACFM-3 reflects to some extent these fast core field variations in the Z component at Hermanus, Hartebeesthoek and Keetmanshoop observatories.
\end{abstract}

Keywords: Harmonic splines, Secular variation, Geomagnetic jerks, South Atlantic Anomaly

\footnotetext{
${ }^{*}$ Correspondence: enahayo@sansa.org.za

${ }^{1}$ South African National Space Agency (SANSA), Hospital Road,

Hermanus 7200, South Africa

Full list of author information is available at the end of the article
}

(C) The Author(s) 2021. Open Access This article is licensed under a Creative Commons Attribution 4.0 International License, which permits use, sharing, adaptation, distribution and reproduction in any medium or format, as long as you give appropriate credit to the original author(s) and the source, provide a link to the Creative Commons licence, and indicate if changes were made. The images or other third party material in this article are included in the article's Creative Commons licence, unless indicated otherwise in a credit line to the material. If material is not included in the article's Creative Commons licence and your intended use is not permitted by statutory regulation or exceeds the permitted use, you will need to obtain permission directly from the copyright holder. To view a copy of this licence, visit http://creativecommons.org/licenses/by/4.0/. 


\section{Graphical Abstract}

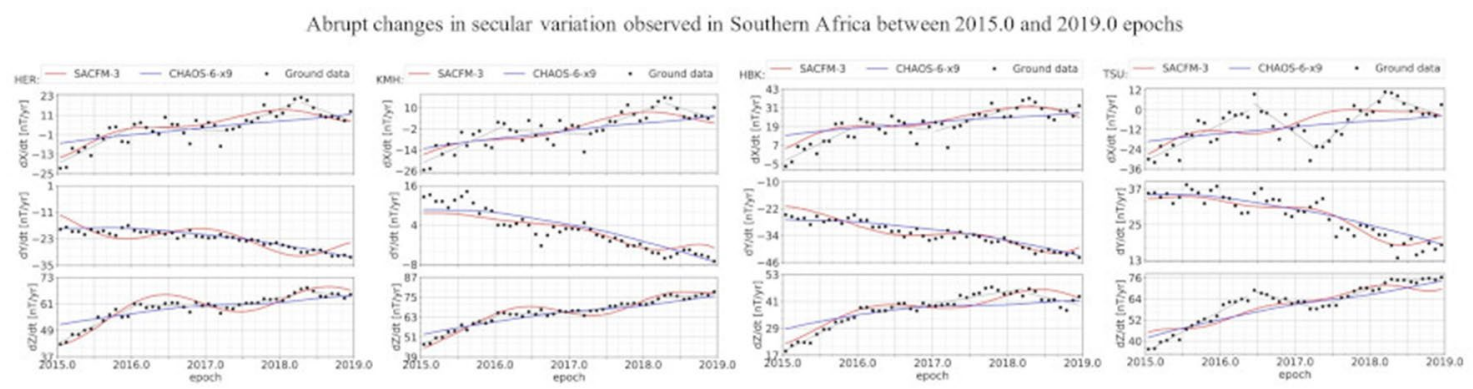

The secular variation trend in X, Y and Z field components between 2015.0 and 2019.0 from the four INTERMAGNET observatories, HER, HBK, TSU and KMH (black dots), with the two models, CHAOS-6-X9 (blue) and SACFM-3 (red). Gray lines represent piecewise linear fits to highlight abrupt changes of trend.

\section{Introduction}

The Earth's magnetic field variation in southern Africa has been marked by unusual changes where the field intensity has been decreasing rapidly in some of its regions. Large parts of the western region that lie in the easternmost part of the South Atlantic Anomaly (SAA), stretching between southern Africa and South America, have recognised more than $20 \%$ decrease of field intensity over the last eight decades (Nahayo et.al., 2018). The southern African region has also been known for many years to have high spatial and temporal field variations with strong abrupt changes in the linear geomagnetic secular variation (Mandea et al., 2007; Kotzé and Korte, 2016; Kotzé, 2020). Some scholars have recently conducted studies of rapid geomagnetic time variations in southern Africa using regional models (Geese et al., 2009, 2011; Nahayo and Kotzé, 2012; Nahayo et al., 2015, 2018).

The study of the high spatial and temporal geomagnetic field variations in this region requires good high-resolution data coverage to shed light on small-scale features of temporal and spatial field variations. A Southern Africa Core Field Model (SACFM-3) was developed combining Swarm satellite and ground-based data recorded between 2014 and 2019. The regional model includes geomagnetic repeat station data that was not used in global models, and it might provide a more detailed view than global models of the geomagnetic field variations in this region.

The SAA is a region of weak geomagnetic field intensity at the Earth's surface that includes most of the South Atlantic Ocean, parts of South America and South Africa. It is commonly attributed to reversed flux patches (RFPs) on the core-mantle boundary (CMB) (e.g. TerraNova et al., 2017). The results of the study of the SAA during the last 200 years by Pavón-Carrasco and De Santis (2016) reveal that the geomagnetic field presents two patches of reversed polarity at the CMB that are growing and moving westward, and the continuous increase of the area covered by the SAA has been interpreted as a possible upcoming geomagnetic transition, such as an excursion or reversal. However, this interpretation is controversial as similar structures in the geological past have been found not to lead directly to transitional events (Brown et al., 2018). Tarduno et al. (2015) propose that the unusual $\mathrm{CMB}$ composition and structure beneath Southern Africa leads to core flux expulsion, resulting in observed low field strengths in this region. Recently, Campuzano et al. (2021) have linked the geomagnetic jerks occurrence with the SAA by studying the changes of the RFPs at the CMB and the area of the SAA at Earth's surface. The SAA region with very weak geomagnetic field, less protected against high-energy particles, is a concern to modern technology as the increased radiation during geomagnetic storms can cause faults in spacecraft electronics and can induce false instrument readings (Schaefer et al., 2016). Therefore, a better understanding of the evolution of the SAA in the region can be very useful in space weather warnings. The continuous monitoring of the change of the Earth's magnetic field in the region is the key to track the evolution of the SAA, and understand its rate of expansion in Southern Africa.

The data used in this study to build the regional model are presented in "Data selection and processing" section, and the harmonic spline method is described in "Methods" section. The SACFM-3 model then is compared to the global models CHAOS $-6-\times 9$ (update from Finlay et al., 2016), IGRF-13 (Alken et al., 2021) and groundbased data recorded at southern Africa INTERMAGNET observatories (Hermanus (HER), Hartebeesthoek (HBK), Tsumeb (TSU) and Keetmanshoop (KMH)) in "Results and discussions" section, and it is used to study the evolution of the SAA at the Earth's surface in the region, and investigate recent observed geomagnetic jerks and other possible abrupt changes in the linear secular variation. The final section presents the conclusion. 


\section{Data selection and processing}

The derivation of the SACFM-3 model is based on three types of data: Swarm satellite data (Olsen et al., 2013), observatory data and field survey data. The Swarm satellite data were selected over the area of interest between $16^{\circ} \mathrm{S}$ and $38^{\circ} \mathrm{S}$ of latitude and $10^{\circ} \mathrm{E}$ and $38^{\circ} \mathrm{E}$ of longitude, on a grid of $1^{\circ} \mathrm{X} 1^{\circ}$, from data that were recorded by three Swarm satellites (Alpha, Bravo and Charlie) between January 2014 and December 2019 (area shown in Fig. 1). The data for the first 3 months from January to March 2014 were not very reliable as the Swarm satellites reached the complete configuration in April 2014. However, there was no noticeable negative influence on the model. Four INTERMAGNET observatories, HER, HBK, TSU and KMH provided data recorded between January 2014 and December 2019. Field survey data recorded at geomagnetic repeat stations between January 2014 and March 2019 were used (Fig. 1). Note that the geomagnetic repeat stations outside the South African border were surveyed only until 2015.

The data selection criteria for night and quiet data, the method of removal of external and lithospheric field contributions were the same for satellite and observatory ground data. Hourly definitive data from observatories were used during data selection and processing. The data selection was conducted using geomagnetic quiet time indices, the Disturbance storm time (Dst) (http://wdc. kugi.kyoto-u.ac.jp/dstdir/) and the planetary K-index (Kp) (https://www.gfz-potsdam.de/en/kp-index/). Data

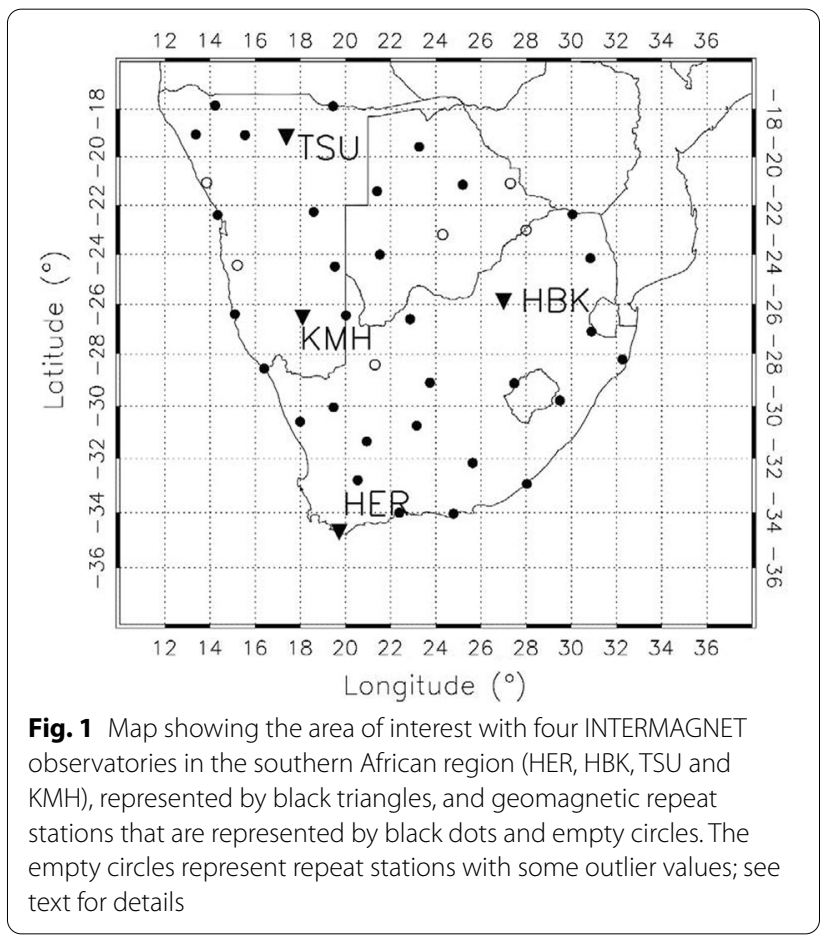

fulfilling the criteria of being recorded during night time between 22:00 and 6:00 LT, $|\mathrm{Dst}| \leq 20 \mathrm{nT}$, and $\mathrm{Kp} \leq 2$ were considered. The lithospheric field contributions were removed using the Potsdam Magnetic Model of the Earth POMME-9 (update from Maus et al., 2006), that resolves the crustal magnetic field to spherical harmonic degree 133 , reaching the small-scale length of $300 \mathrm{~km}$. The field contributions of spherical harmonic degrees above 15 were removed from data.

Modelling data by harmonic splines requires solving a square system of equations with dimension equal to the number of data points (Shure et al., 1982). Using a reasonable number of evenly distributed data centres supports a good data coverage and reduces the complexity of the problem to solve. The satellite data processing was conducted to generate the model input data by creating data bins of $0.1^{\circ}$ radius on the grid of $1^{\circ} \mathrm{X} 1^{\circ}$. Data in the same data bin recorded at the same epoch (e.g. 2014.015, within the period of one day) were averaged to obtain a single value at the centre of data bin. The number of data points that are averaged is on the order of 2 to 4 , and the average total number of visits to one centre by the three satellites, Alpha, Bravo and Charlie, during the entire period 2014-2019, is 61. The averaging of data recorded at the same epoch makes the average total number of data points recorded at one centre, at different epochs to be in order of $20(61 / 3)$. The absolute average scatter of values of $\mathrm{X}, \mathrm{Y}, \mathrm{Z}$ and altitude of data points in the same bin and recorded at the same epoch were $6.3 \mathrm{nT}, 6.9 \mathrm{nT}, 2.5 \mathrm{nT}$ and $4 \mathrm{~m}$, respectively. In this process, data points with different epochs and altitudes were produced at each data bin centre. The observatory hourly data were averaged to calculate monthly values for the model input data. The collection of the field survey data was conducted recording night field variations for one day repeat station visits and taking absolute observations late in the evening and early morning. The main field values for a repeat station were calculated by averaging absolute minute values for a 10-h night time interval, between 8:00 P.M. and 6:00 A.M. LT (Korte et al., 2007). Table 1

Table 1 The three types of model input data comprising satellite, observatory, and field survey data

\begin{tabular}{lccc}
\hline & Satellite data & $\begin{array}{l}\text { Observatory } \\
\text { data }\end{array}$ & $\begin{array}{l}\text { Field } \\
\text { survey } \\
\text { data }\end{array}$ \\
\hline Number of data centres & 667 & 4 & 37 \\
Number of data points & 13,343 & 312 & 129 \\
Weight of data & 40 & 100 & 60 \\
\hline
\end{tabular}

Their respective numbers of data centres, and the chosen weight for each data set are presented in the table 
shows the three categories of model input data with their respective numbers of data centres and points, and chosen weights. The selection of data weights was conducted assuming that during data averaging, the external field noise was cancelled out better in observatory data and field survey data than in satellite data. Besides, ground-based data were given higher weights relative to satellite data to improve the model performance at Earth's surface. The data weight selection took also into account the reliability of long-term observatory data over field survey data and the large number of satellite data points dominating the model input data.

\section{Methods}

The regional model was derived from Swarm satellite and ground-based data using harmonic spline functions (Shure et al., 1982; Lesur, 2006). The technique allows the integration of data recorded at different altitudes and epochs, thus making it possible to combine satellite and ground-based data in the model derivation. A summary of the spatial harmonic spline method is presented here, and the time dependency for the model is introduced at the end.

According to Lesur (2006) and Geese et al. (2009), for each data location $j$ defined by its geocentric coordinates $\left(\vartheta_{j}, \varphi_{j}, r_{j}\right)$, the Earth's magnetic field can be written as: localised functions. In a compact form, the Earth's magnetic field is given by the following equation:

$$
B(\vartheta, \phi, r)=-\sum \alpha_{j} \nabla F_{j}^{L}(\vartheta, \phi, r),
$$

where $\alpha_{j}$ are the coefficients of the model and $\nabla F_{j}^{L}(\vartheta, \phi, r)$ are harmonic spline functions.

Equation (1) is time independent, it defines a linear system of equations where $\alpha_{j}^{r}, \alpha_{j}^{\vartheta}$ and $\alpha_{j}^{\phi}$ are unknowns. This linear system is square and can be solved directly. For time representation, we expand each of the coefficients $\alpha_{j}^{r}, \alpha_{j}^{\vartheta}$ and $\alpha_{j}^{\phi}$ on a basis of B-splines, i.e. piecewise polynomials between spline knots:

$$
\alpha_{j}^{r}=\sum_{k}^{n_{\text {knots }}} \beta_{k_{j}}^{r} b_{k}(t)
$$

and $\alpha_{j}^{\vartheta}$ and $\alpha_{j}^{\phi}$ are expanded similarly.

The maximum degree of expansion of internal sources was set to 13 for the core field. For the time representation, order six B-splines with spline knots spaced at 1-year intervals between 2014.0 and 2020.0 are used. A linear system is built from Eqs. (1) and (6) and solved for the unknown model parameters $\beta_{k_{j}}^{r}, \beta_{k_{j}}^{\vartheta}$ and $\beta_{k_{j}}^{\phi}$ as defined in Eq. (6).

$$
B(\vartheta, \phi, r)=-\nabla\left\{\sum_{j} \alpha_{j}^{r} F_{j}^{L_{r}}(\vartheta, \phi, r)+\sum_{j} \alpha_{j}^{\vartheta} F_{j}^{L_{\vartheta}}(\vartheta, \phi, r)+\sum_{j} \alpha_{j}^{\phi} F_{j}^{L \phi}(\vartheta, \phi, r)\right\},
$$

where the functions $F_{j}^{L_{r}}(\vartheta, \phi, r), F_{j}^{L \vartheta}(\vartheta, \phi, r)$ and $F_{j}^{L \phi}(\vartheta, \phi, r)$ are defined as follows:

$$
\begin{aligned}
& F_{j}^{L_{r}}=a \sum_{l, m}^{L} f_{l}(l+1)\left[\left(\frac{a}{r_{j}}\right)^{l+2} Y_{l}^{m}\left(\vartheta_{j}, \phi_{j}\right)\right]\left(\frac{a}{r}\right)^{l+1} Y_{l}^{m}(\vartheta, \phi), \\
& F_{j}^{L_{\vartheta}}=a \sum_{l, m}^{L} f_{l}\left[\left(\frac{a}{r_{j}}\right)^{l+2} \partial_{\vartheta} Y_{l}^{m}\left(\vartheta_{j}, \phi_{j}\right)\right]\left(\frac{a}{r}\right)^{l+1} Y_{l}^{m}(\vartheta, \phi), \\
& F_{j}^{L \phi}=a \sum_{l, m}^{L} f_{l}\left[\left(\frac{a}{r_{j}}\right)^{l+2} \frac{\partial \phi}{\sin \vartheta_{j}} Y_{l}^{m}\left(\vartheta_{j}, \phi_{j}\right)\right]\left(\frac{a}{r}\right)^{l+1} Y_{l}^{m}(\vartheta, \phi),
\end{aligned}
$$

where $\sum_{l, m}^{L}$ denotes the double sum $\sum_{l=1}^{L} \sum_{m=-l}^{l}, \vartheta, \phi$, and $r$ are the geocentric colatitude, longitude and radius, respectively, a is the Earth's reference radius $(6371.2 \mathrm{~km})$, $Y_{l}^{m}(\vartheta, \phi)$ are the usual Schmidt semi-normalised spherical harmonic functions of degree $l$ and order $m, L$ is the maximum degree of expansion of internal sources and $f_{l}=\frac{2 l+1}{4 \Pi(l+1)^{4} l^{2}}$. The parameter $f_{l}$ defines the shape of the

\section{Results and discussion}

The developed regional core field model, SACFM-3, is based on harmonic spline fitting of vector Swarm satellite data and ground-based data recorded between January 2014 and December 2019. The root mean square (rms) values of the difference between observed and model values were $10.3 \mathrm{nT}, 6.7 \mathrm{nT}$ and $6.6 \mathrm{nT}$ for the $\mathrm{X}, \mathrm{Y}$ and $\mathrm{Z}$ components, respectively. The following comparison to global models and data is based on the time interval 2014.5-2019.5 where the regional model is considered to be reliable. The model evaluation was conducted by comparison to the global models CHAOS-6- $\times 9$ (update from Finlay et al., 2016), IGRF-13 (Alken et al., 2021) and to the data. CHAOS is a continuous model and IGRF, the International Geomagnetic Reference Field, consists of 5 -year snapshots only. Table 2 shows the rms values calculated at 667 data centres between two models at $445 \mathrm{~km}$ (average altitude of used satellite data recorded within the range of $262 \mathrm{~km}$ ) and $0 \mathrm{~km}$ altitudes. The differences for each component do not vary much over the 
Table 2 The rms values of the differences between the SACFM-3 and CHAOS- $6-\times 9$ models at 667 satellite data centres on $1^{\circ} \times 1^{\circ}$ grid, covering the whole modelled area, at $445 \mathrm{~km}$ and $0 \mathrm{~km}$ of altitude, and calculated at different epochs between 2014 and 2019.

\begin{tabular}{|c|c|c|c|c|c|c|c|}
\hline Altitude & Comp & 2014.5 & 2015.5 & 2016.5 & 2017.5 & 2018.5 & 2019.5 \\
\hline \multirow[t]{4}{*}{$445 \mathrm{~km}$} & $\Delta x$ & 89 & 96 & 95 & 95 & 89 & 92 \\
\hline & $\Delta Y$ & 22 & 23 & 23 & 23 & 24 & 23 \\
\hline & $\Delta Z$ & 71 & 76 & 73 & 74 & 72 & 71 \\
\hline & $\Delta \mathrm{F}$ & 23 & 24 & 23 & 23 & 23 & 22 \\
\hline \multirow[t]{4}{*}{$0 \mathrm{~km}$} & $\Delta X$ & 118 & 125 & 123 & 123 & 117 & 120 \\
\hline & $\Delta Y$ & 43 & 48 & 45 & 47 & 46 & 47 \\
\hline & $\Delta Z$ & 89 & 88 & 88 & 88 & 86 & 84 \\
\hline & $\Delta \mathrm{F}$ & 53 & 49 & 49 & 50 & 49 & 48 \\
\hline
\end{tabular}

The rms values in the table are in $\mathrm{nT}$

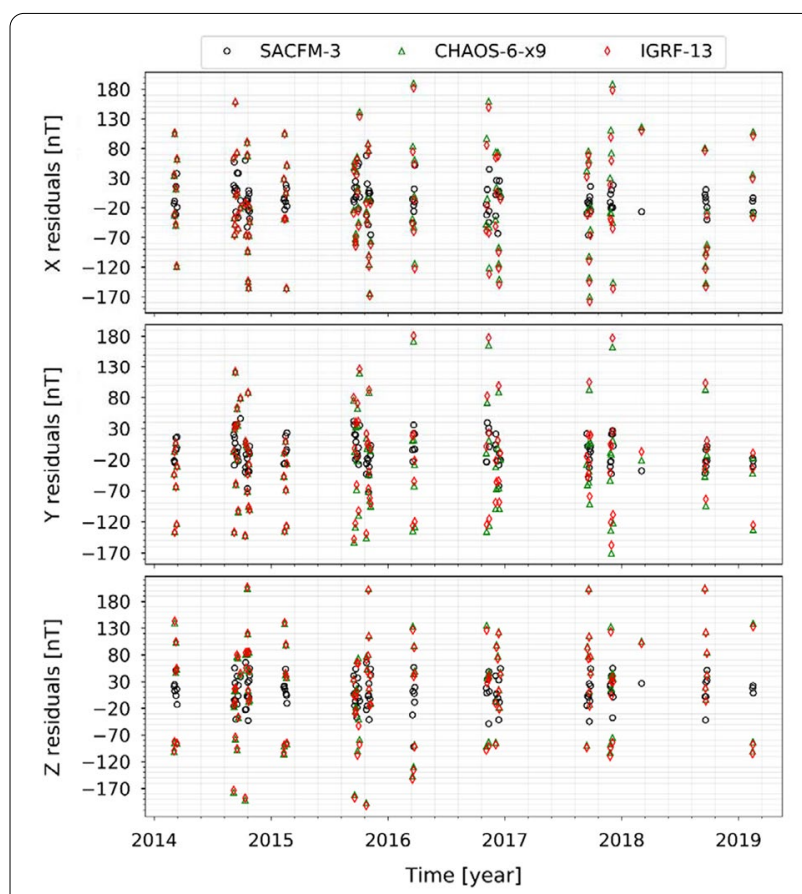

Fig. 2 Residuals of the differences between ground field survey data and models SACFM-3, CHAOS-6- $\times 9$ and IGRF-13

time interval (2014.5-2019.5). The Y component and the total intensity $\mathrm{F}$ show small differences relative to the other two components $\mathrm{X}$ and $\mathrm{Z}$.

The comparative evaluation of the SACFM-3 model and global models CHAOS-6- $\times 9$ and IGRF-13, with the help of field survey data collected at geomagnetic repeat stations, is presented in Fig. 2. In this comparison, 113 out of 129 available data points of survey data between 2014 and 2019 were used. No crustal field or external field contributions were removed from these field survey data that were used in the comparison. The remaining 16 data points have absolute residual values with the global models that are above $220 \mathrm{nT}$, hence they were
Table 3 The rms values of the differences between 113 survey data points and model predicted values over the period 20142019

\begin{tabular}{llll}
\hline Component & SACFM-3 & CHAOS-6- $\times \mathbf{9}$ & IGRF-13 \\
\hline$\Delta X(n T)$ & 25.1 & 78.5 & 78.9 \\
$\Delta Y(n T)$ & 24.3 & 76.6 & 75.2 \\
$\Delta Z(n T)$ & 29.0 & 83.9 & 83.6 \\
\hline
\end{tabular}

These differences (residuals) are presented in Fig. 2

considered as outliers for a better data visualisation in Fig. 2. A relatively higher constant crustal offset at some repeat stations is thought to be the source of these large differences. Figure 1 shows 6 repeat stations as empty circles that are the source for these 16 data points. It is worth noting that these survey data were used as input data for the regional model SACFM-3. Table 3 shows that the difference between field survey data and the regional model SACFM-3 calculated values yields relatively small rms values for residuals, whereas the global models CHAOS-6- $\times 9$ and IGRF-13 have relatively high and similar values.

For the overall performance over the modelled area, Fig. 3 presents the maps of $\mathrm{Z}$ and $\mathrm{F}$ of the differences between SACFM-3 and CHAOS- $6-\times 9$ models for epoch 2019.0 at $0 \mathrm{~km}$ altitude. The relatively big differences are found in the left and right top corners of the modelled area, and these might be mostly due to lack of ground data, otherwise there is a good agreement between these two models.

Furthermore, the investigation of secular variation in the region was conducted using monthly observatory and model values, and secular variation values were calculated for each component as follows:

$\frac{d B}{d t}=\dot{B}(t)=\frac{B(t+6)-B(t-6)}{1 \text { year }},(B=X, Y$ or $Z)$, where the unit of $t$ is month (e.g. Chulliat et al., 2010).

Besides the use of ground-based data recorded at four INTERMAGNET observatories (HER, HBK, TSU and 


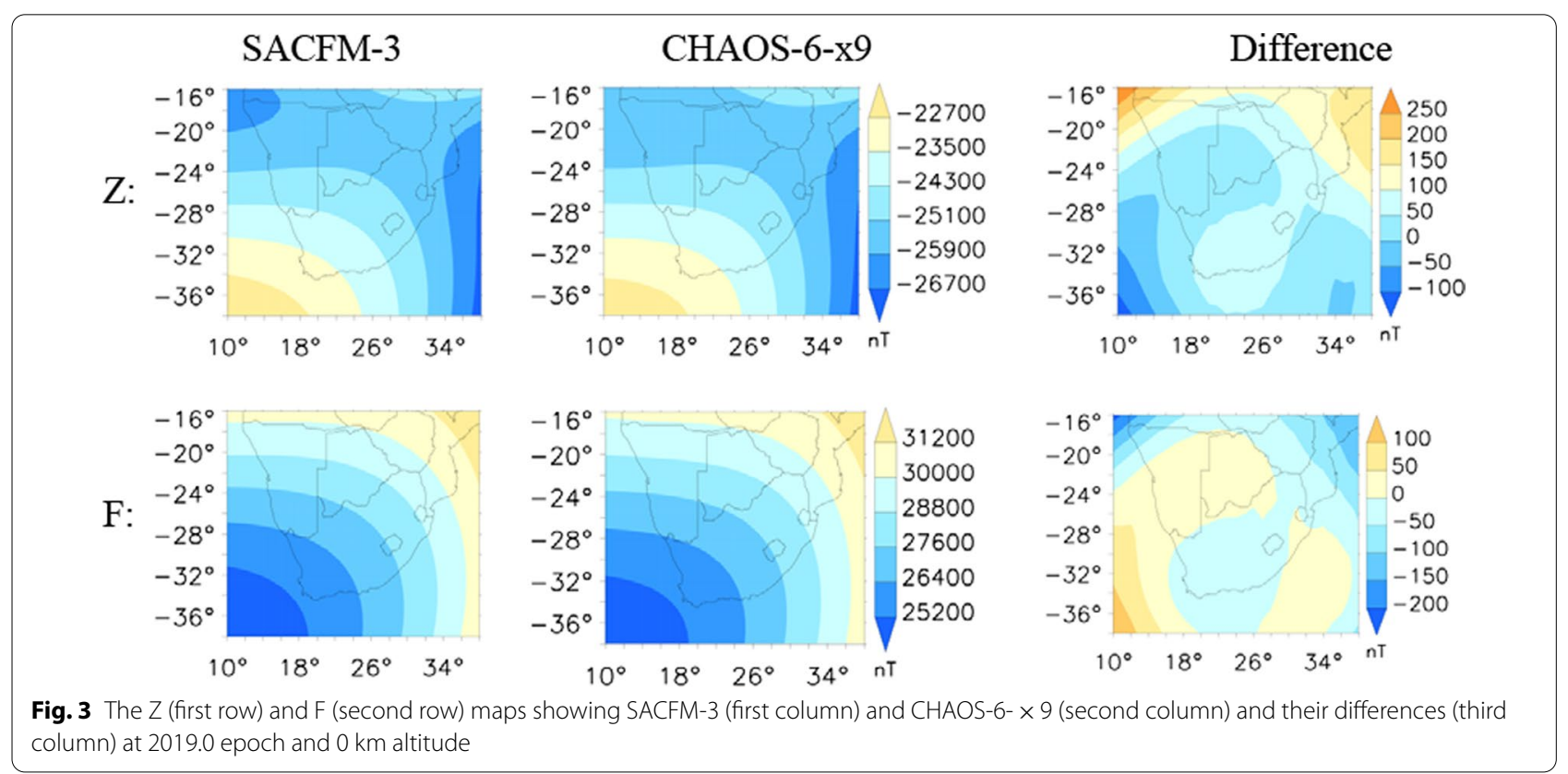

$\mathrm{KMH})$ to perform the comparative evaluation of the regional model, recorded satellite data were used by creating virtual observatories (VObs) at satellite altitude $(467 \mathrm{~km})$ over the positions of four INTERMAGNET observatories. In the interest of minimising the data correction, the virtual observatory altitude is the average of the altitudes of selected data within $0.2^{\circ}$ of radius at the positions of HER, HBK, TSU and KMH observatories between 2014 and 2019. The selected data were recorded at different positions (latitude, longitude, altitude) and epochs. From data points with the same epochs only those with geographic coordinates closest to the reference ground observatory position were kept. They were corrected by first calculating the difference between magnetic values at two positions (virtual observatory and actual selected data positions) at the same epoch using the global model IGRF-13. The new satellite value at a virtual observatory is the recorded satellite data value plus the difference value between the above mentioned positions. This process is presented in the following equation:

$$
D_{\mathrm{vo}}=D_{\mathrm{s}}+\left(I_{\mathrm{vo}}-I_{\mathrm{s}}\right),
$$

where $D_{v o}$ is data value at a virtual observatory and at a particular epoch, $D_{s}$ a recorded satellite data value, $I_{v o}$ and $I_{s}$ are IGRF-13 calculated values at the virtual observatory and the satellite data value positions, respectively.

The calculation of secular variation values was performed applying a similar approach that was used for ground-based and model data. But, the time interval between the calculated consecutive virtual observatory data is not constant. The time interval between a pair of two data points used to calculate secular variation values was not exactly 1 year, but these pairs were selected such that the difference in their respective epochs is as close as possible to 1 year. The following equation was used:

$$
\frac{d B}{d t}=\dot{B}\left(\frac{t_{2}+t_{1}}{2}\right)=\frac{B\left(t_{2}\right)-B\left(t_{1}\right)}{t_{2}-t_{1}},(B=X, \text { Yor } Z),
$$

where $t_{1}$ and $t_{2}$ are the respective epochs of the two considered data points.

The results in Figs. 4 and 5 demonstrate the high temporal variation in the secular variation over Southern Africa. There is a good agreement between secular variation values derived from SACFM-3 and observatory data in all components, especially at HBK and TSU. Despite the low variability in the CHAOS $-6-\times 9$ secular variation prediction, both models and observatory data show the same trend of the secular variation over the entire period 2015.0-2019.0. The observed high variability in the SACFM-3 secular variation values in some field components indicates that external field contributions might not have been fully removed from the model input data. The positive rate of change in the $\mathrm{Z}$ component has been increasing at all observatories, and its values are relatively higher at HER, TSU and KMH in the western part of the region. As $Z$ is negative in this area, the magnitude value of the $\mathrm{Z}$ component has been decreasing over the years in the region with the western part of Southern Africa more affected. At all four observatories (HER, HBK, KMH and TSU), the rate of change in the $\mathrm{X}$ component has been or is about to change from negative to positive values. In 

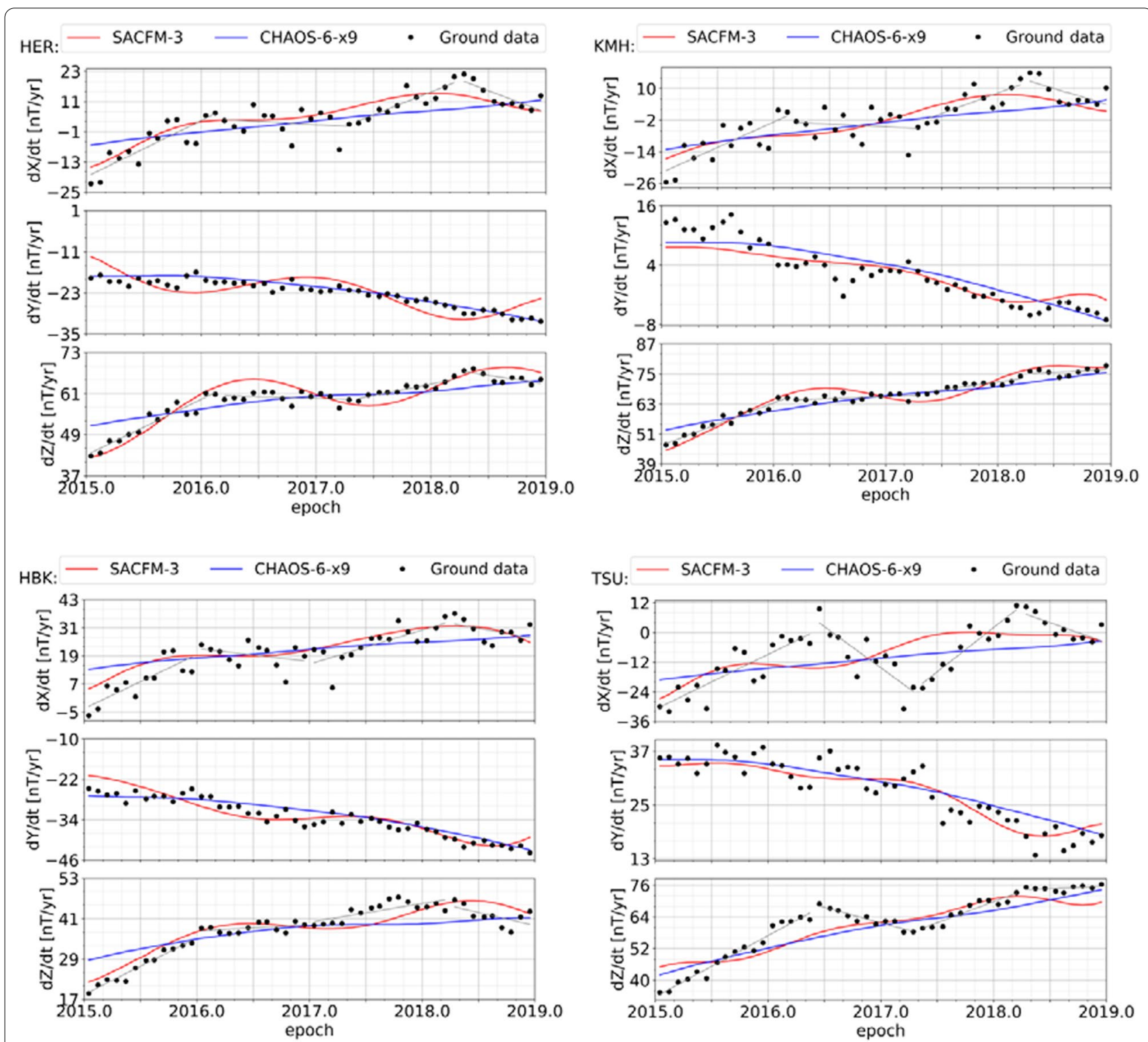

Fig. 4 The secular variation trend in $X, Y$ and $Z$ field components between 2015.0 and 2019.0 from the four INTERMAGNET observatories, HER, HBK, TSU and KMH (black dots), with the two models, CHAOS-6- $\times 9$ (blue) and SACFM-3 (red). Gray lines represent piecewise linear fits to highlight abrupt changes of trend

HER and HBK negative secular variation in $Y$ has been intensifying, whereas at TSU the positive secular variation has been decreasing and at $\mathrm{KMH}$ the secular variation in $\mathrm{Y}$ has changed from positive to negative values. The positive rate of change in the Y component at TSU throughout the entire period shows how the magnitude of $Y$ has been decreasing in the north-western part of the region. On the other hand, the negative rate of change in the Y component at HER and HBK explains the increasing of the $\mathrm{Y}$ in magnitude in the southern and eastern regions.
Some abrupt changes in the linear secular variation, known as geomagnetic jerks or geomagnetic impulses (Mandea et al., 2010), are observed in the ground data in Fig. 4. A linear fitting of data segments was used to identify the sudden change events in secular variation. In Fig. 4, TSU ground data show clearly V-shaped changes in secular variation indicating the occurrence of the 2016 geomagnetic jerk in the $\mathrm{X}$ and $\mathrm{Z}$ component that has recently been reported by Kotzé (2020) and Finlay et al (2020). Similar changes are equally identified in the same components at HER, HBK and KMH, though with lower 

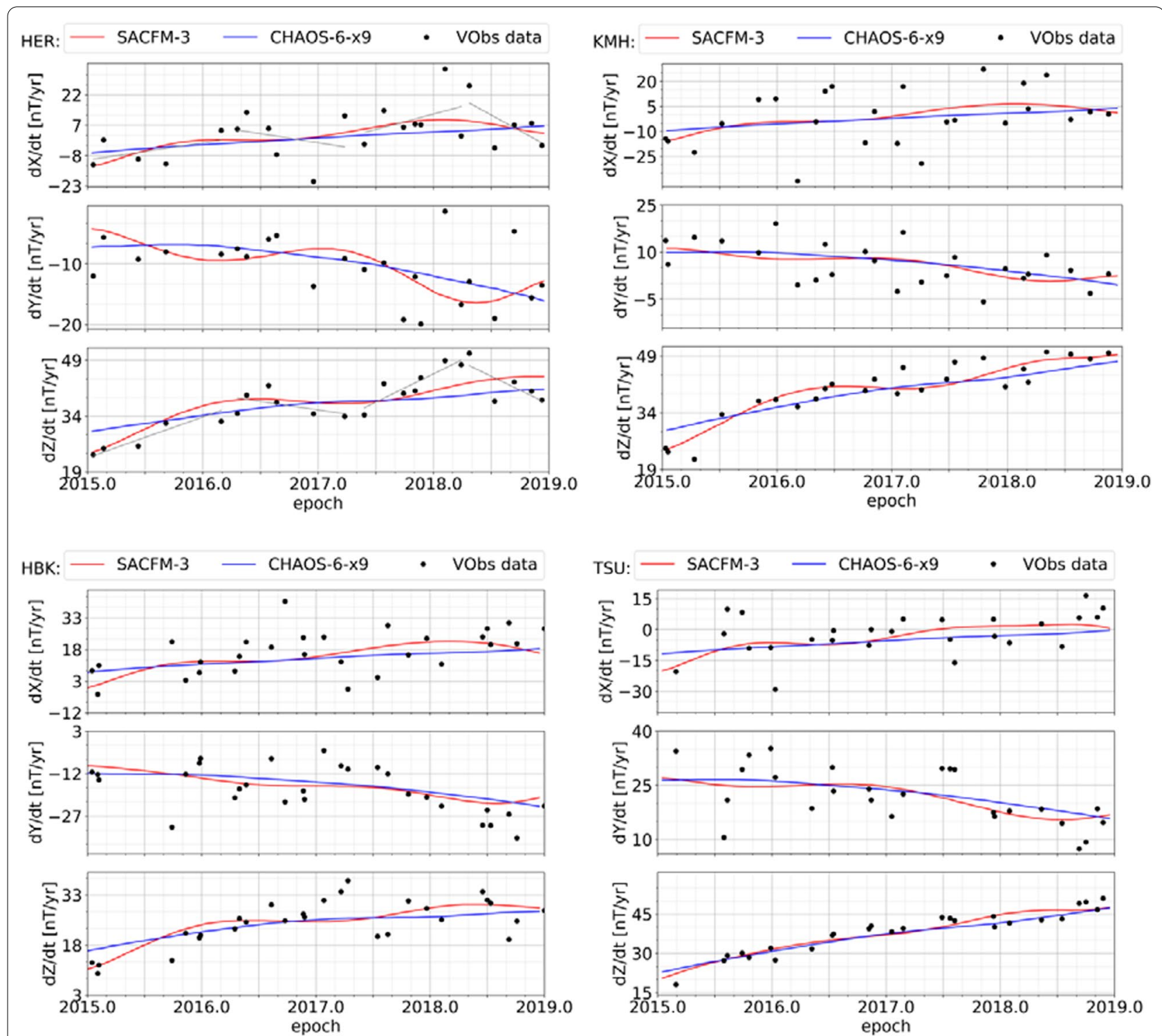

Fig. 5 The secular variation trend in $X, Y$ and $Z$ field components between 2015.0 and 2019.0 epochs at $476 \mathrm{~km}$ altitude from the virtual observatory satellite data (black dots, see text) at the positions of the INTERMAGNET stations HER, HBK, TSU and KMH and the models SACFM-3 (red) and CHAOS-6- $\times 9$ (blue). Gray lines represent piecewise linear fits to highlight abrupt changes of trend

amplitude of change. The earlier reported 2017 geomagnetic jerk by Duan and Huang (2020) is also identified at TSU in the $\mathrm{X}$ and $\mathrm{Z}$ components, and it is observed only in the $\mathrm{X}$ component at HER, HBK and KMH. Another secular variation change event in 2018 is observed in the X component clearly at HER, TSU and KMH, and to some extent at HBK. The SACFM-3 model can pick up the 2016, 2017 and 2018 abrupt changes in the X and Z components at HER and HBK with a slight mismatch in the order of less than 0.5 year from the epoch of the event in the ground data. Figure 5 presents the secular variation values at virtual observatories at $467 \mathrm{~km}$ altitude where the regional model SACFM-3 (built mostly from swarm satellite data) is considered to perform better. The SACFM-3 fits well the virtual observatory data especially in the $\mathrm{Z}$ component. But, the high scatter and limited number of virtual data points make impossible to identify the abrupt changes, except the observed 2016, 2017 and 2018 abrupt changes in the $\mathrm{Z}$ component at HER. The regional model features at satellite altitude are more or less similar to the ones observed at the ground level. The least contaminated component $\mathrm{Z}$ indicates the three abrupt change events (2016, 2017 and 2018) in secular variation at all virtual observatories. 
Southern Africa, especially its western part, is found in the South Atlantic Anomaly region where the field intensity has been very weak compared to other places of the same latitude. Thus, it is very important to evaluate how the field intensity has been changing in the region. Figure 6 presents the maps of field components $\mathrm{X}, \mathrm{Y}$ and $\mathrm{Z}$, the total field intensity $\mathrm{F}$ and the angle of declination at 2014.5 and 2019.5 epochs and the maps of differences between the values at these two epochs. The 5-year change values in the third column of Fig. 6 show that the magnitude values of the $\mathrm{X}$ and $\mathrm{Y}$ components have decreased in a small western part of the region between 2014.5 and 2019.5, and the magnitude value of the $\mathrm{Z}$ component has decreased almost in the entire region except the small western edge of the Indian ocean. The rate of decrease in the $\mathrm{Z}$ component is between 45 and

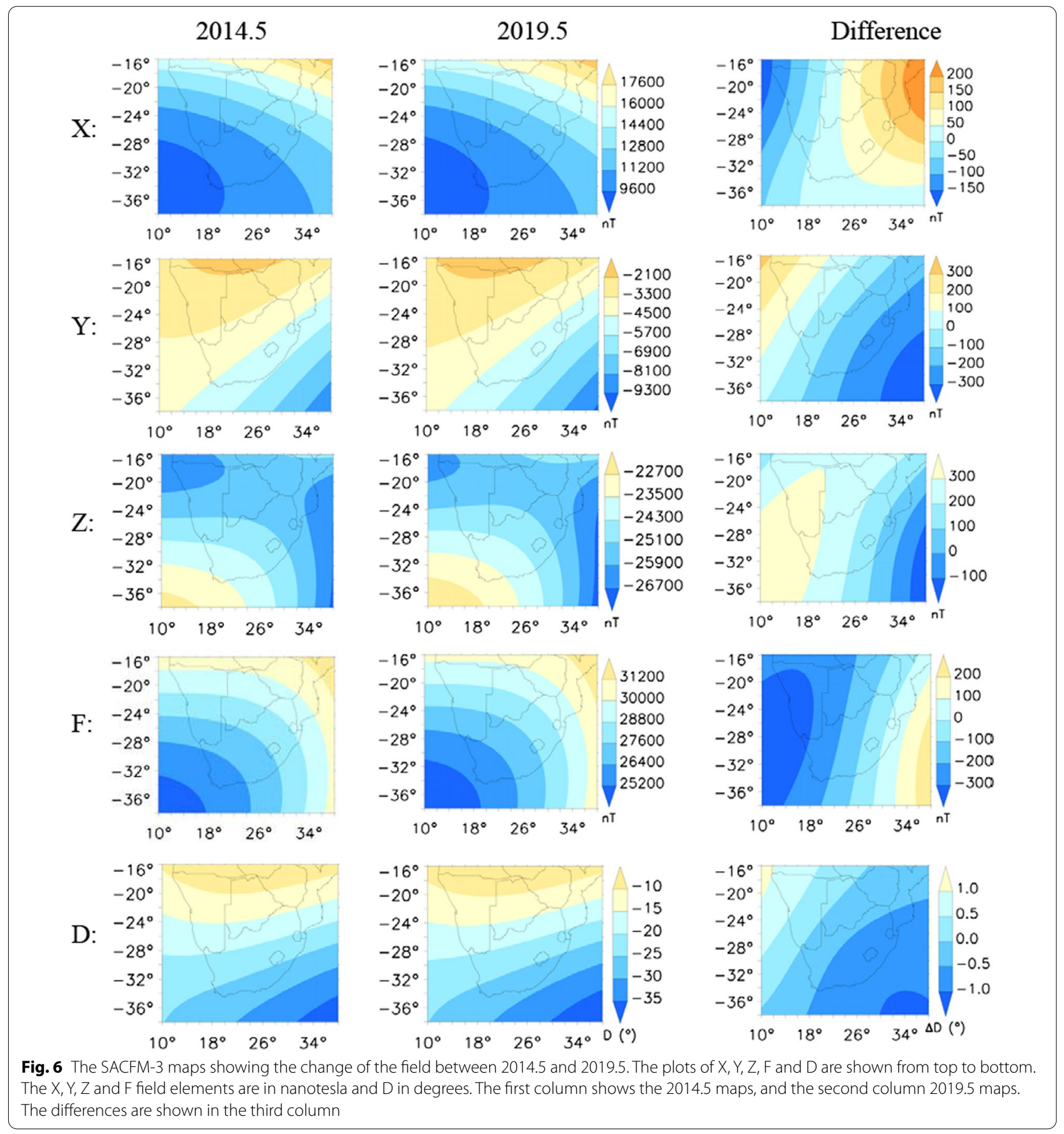


$60 \mathrm{nT} /$ year on average in the most western part of the region. As described above, the $\mathrm{Z}$ component is a big contributor to the decrease of the field intensity $F$ for which the average rate of decrease over 5 years can reach $60 \mathrm{nT} /$ year in some parts of the south-western region. In this SAA region, there is a noticeable growth of low field intensity strength area from the south-western corner of the modelled area expanding towards the north and eastern regions (Fig. 6). This confirms the findings of Finlay et al (2020) that, in the region of SAA, the weakest field region has over the past 6 years slowly extended eastwards from South America towards South Africa, at latitudes between 30 and $45^{\circ}$ south.

The magnetic declination (D) has been decreasing in the north-western part of the region, and increasing in the south eastern part. The change in 5 years is more than $0.5^{\circ}$ in the north-western corner region and most of the south eastern region.

\section{Conclusion}

A regional field model SACFM-3 over Southern Africa was derived from Swarm satellite and ground-based data using harmonic splines. A comparative evaluation was conducted using global models CHAOS-6- $\times 9$ and IGRF-13, which yielded a good agreement between these models. A detailed investigation of spatial and temporal magnetic field variations between 2014.5 and 2019.5 reveals that the $\mathrm{Z}$ component strength has decreased in the whole region (reaching more than $70 \mathrm{nT} /$ year in 2019 at TSU and $\mathrm{KMH}$ ), and becoming the main contributor of the decrease of the total intensity $\mathrm{F}$ in the central and western regions (0-300 nT over 5 years). Other components $\mathrm{X}$ and $\mathrm{Y}$ have experienced a decrease in one part of the region and an increase in another. It is worth mentioning the decrease (reaching 4\%) and increase (reaching $6 \%$ ) in magnitude of the $Y$ component over 5 years in the north western and south eastern regions, respectively. In addition, the secular variation patterns at four magnetic observatories (HER, HBK, TSU and KMH) between 2015.0 and 2019.0 epochs show the high spatial and temporal magnetic field variations in Southern Africa. Therefore, it is advisable to keep on monitoring the changes of magnetic field in the region to avoid errors that may result in relying on linear secular variation predictions.

The previously reported abrupt changes in the secular variation in 2016 (Kotzé, 2020; Finlay et al, 2020) and in 2017 (Duan and Huang, 2020) are clearly observed in the ground data at TSU observatory in the $\mathrm{X}$ and $\mathrm{Z}$ components (Fig. 4). Similar abrupt changes are identified in the same components at HER, HBK and KMH without an evident sharp V-shape. The observed abrupt change in the secular variation in 2018 in the $\mathrm{X}$ component at all observatories needs further investigation to ascertain if it is related to the change in the core field. In contrast to the global CHAOS model, the SACFM-3 model shows some indication of these abrupt secular variation change events, especially in the $\mathrm{Z}$ component for the locations of HER, HBK and KMH. An improved regional main field model over southern Africa might contribute to a good understanding of the evolution of the reversed flux patches in the CMB below the eastern part of the SAA. This information might help in predicting future changes to the SAA, thus playing an important role to mitigate the increasing radiation effects in spacecraft flying over the region. The investigation of the fast core field variations in southern Africa requires a good performance in removing external field contributions from satellite and ground-based data. It is sometimes very difficult to know the origin of the observed fast field variations in the secular variation, whether they are fast core field variations or they are just related to external field noise. The use of the time derivative of Dst index (Kauristie et al., 2017) in data selection and the removal of the external field contributions from data using RC index (Onovughe, 2018) can improve the quality of data for internal field modelling.

\section{Supplementary Information}

The online version contains supplementary material available at https://doi. org/10.1186/s40623-021-01563-5.

Additional file 1. SACFM-3 model parameters.

Additional file 2. Number of data points per centre.

Additional file 3. SACFM-3 model input data.

\section{Acknowledgements}

The work of the European Space Agency of making available high-quality Swarm satellite data is appreciated. The GFZ German Research Centre for Geosciences in Potsdam is acknowledged for the provided support in running and maintaining the KMH magnetic observatory. SANSA staff responsible for the acquisition and processing of geomagnetic field data from $\mathrm{HER}, \mathrm{HBK}, \mathrm{KMH}$ and TSU is acknowledged.

\section{Authors' contributions}

EN drafted the initial document and made all the plots and tables. MK has been involved in the interpretation of results and critically revising sections for scientific content. All authors read and approved the final manuscript.

\section{Funding}

Not applicable.

\section{Availability of data and materials}

All magnetic observatory data used in this investigation are available at https://intermagnet.org/ and field survey data at http://www.geomag.bgs. ac.uk/data_service/data/surveydata.shtml. ESA Swarm data are available at https://earth.esa.int/eogateway/missions/swarm/data, CHAOS: http://www. spacecenter.dk/files/magnetic-models/CHAOS-7/, and POMME: http://geomag.colorado.edu/pomme-6-magnetic-model-of-the-earth.html.

\section{Declarations}

Competing interests

The authors declare that they have no competing interests. 


\section{Author details}

1South African National Space Agency (SANSA), Hospital Road, Hermanus 7200, South Africa. ${ }^{2}$ GFZ German Research Centre for Geosciences, Telegrafenberg, 14473 Potsdam, Germany.

Received: 16 September 2021 Accepted: 14 December 2021 Published online: 04 January 2022

\section{References}

Alken P, Thébault E, Beggan CD et al (2021) International geomagnetic reference field: the thirteenth generation. Earth Planets Space 73:49. https:// doi.org/10.1186/s40623-020-01288-x

Brown MC, Korte M, Holme R, Wardinski I, Gunnarson S (2018) Earth's magnetic field is probably not reversing. Proc Nat Acad Sci U S A 115:5111-5116. https://doi.org/10.1073/pnas.1722110115

Campuzano SA, Pavón-Carrasco FJ, De Santis A, González-López A, Qamili E (2021) South Atlantic anomaly areal extent as a possible indicator of geomagnetic jerks in the satellite era. Front Earth Sci 8:563. https://doi. org/10.3389/feart.2020.607049

Chulliat A, Thébault E, Hulot G (2010) Core field acceleration pulse as a common cause of the 2003 and 2007 geomagnetic jerks. Geophys Res Lett 37:L07301. https://doi.org/10.1029/2009GL042019

Duan P, Huang C (2020) Intradecadal variations in length of day and their correspondence with geomagnetic jerks. Nat Commun 11:2273. https://doi. org/10.1038/s41467-020-16109-8

Finlay CC, Olsen N, Kotsiaros S, Gillet N, Toeffner-Clausen L (2016) Recent geomagnetic secular variation from Swarm and ground observatories as estimated in the CHAOS-6 geomagnetic field model. Earth Planets Space 68:112. https://doi.org/10.1186/s40623-016-0486-1

Finlay CC, Kloss C, Olsen N et al (2020) The CHAOS-7 geomagnetic field model and observed changes in the South Atlantic Anomaly. Earth Planets Space 72:156. https://doi.org/10.1186/s40623-020-01252-9

Geese A, Hayn M, Mandea M, Lesur V (2009) Regional modelling of the Southern African geomagnetic field using harmonic splines. Geophys J Int 200:1-16. https://doi.org/10.1111/j.1365-246X.2010.04575.x

Geese A, Korte M, Kotzé PB, Lesur V (2011) Southern African geomagnetic secular variation from 2005 to 2009. S Afr J Geol 114:515-524. https://doi. org/10.2113/gssajg.114.3-4.515

Kauristie K, Morschhauser A, Olsen N, Finlay C, McPherron R, Gjerloev JW, Opgenoorth $\mathrm{H}$ (2017) On the usage of geomagnetic indices for data selection in internal field modelling. Space Sci Rev 206:61-90. https://doi. org/10.1007/s11214-016-0301-0

Korte M, Mandea M, Kotzé PB, Nahayo E, Pretorius B (2007) Improved observations at the southern African geomagnetic repeat station network. S Afr J Geol 110:175-186. https://doi.org/10.2113/gssajg.110.2-3.175

Kotzé PB (2020) Geomagnetic secular variation changes in Southern Africa during the SWARM period 2013-2018. Ann Geophys 63(2):PA212. https:// doi.org/10.4401/ag-8126

Kotzé PB, Korte M (2016) Morphology of the southern African geomagnetic field derived from observatory and repeat station survey observations: 2005-2014. Earth Planets Space 68(1):1-14. https://doi.org/10.1186/ s40623-016-0403-7

Lesur V (2006) Introducing localised constraints in global geomagnetic field modelling. Earth Planets Space 58:477-483. https://doi.org/10.1186/ BF03351943

Mandea M, Korte M, Mozzoni D, Kotzé PB (2007) The magnetic field changing over the southern African continent-a unique behaviour. S Afr J Geol 110:193-202. https://doi.org/10.2113/gssajg.110.2-3.193

Mandea M, Holme R, Pais A, Pinheiro K, Jackson A, Verbanac G (2010) Geomagnetic jerks: rapid core field variations and core dynamics. Space Sci Rev 155:147-175. https://doi.org/10.1007/s11214-010-9663-x

Maus S, Rother M, Stolle C, Mai W, Choi S, Luhr H, Cooke D, Roth C (2006) Third generation of the potsdam magnetic model of the Earth (POMME). Geochem Geophys Geosystems 7(7):Q077008. https://doi.org/10.1029/ 2006GC001269

Nahayo E, Kotzé PB (2012) Polynomial modelling of CHAMP satellite data to investigate rapid secular variation fluctuations over southern Africa during 2003 and 2004. Earth Planets Space 64:595-603. https://doi.org/10. 5047/eps.2012.03.001
Nahayo E, Kotze PB, McCreadie H (2015) A southern Africa harmonic spline core field model derived from champ satellite data. J Atmos Solar Terr Phys 123:13-21. https://doi.org/10.1016/j.jastp.2014.12.002

Nahayo E, Kotzé PB, Korte M, Webb SJ (2018) A harmonic spline magnetic main field model for Southern Africa combining ground and satellite data to describe the evolution of the South Atlantic Anomaly in this region between 2005 and 2010. Earth Planets Space 70:30. https://doi. org/10.1186/s40623-018-0796-6

Olsen N, Friis-Christensen E, Floberghagen R, Alken P, Beggan CD, Chulliat A, Doornbos E, Da Encarnação JT, Hamilton B, Hulot G, Van den ljssel J, Kuvshinov A, Lesur V, Lühr H, Macmillan S, Maus S, Noja M, Olsen PEH, Park J, PInk G, Püthe C, Rauberg J, Ritter M, Sabaka TJ, Schachtschneider R, Sirol O, Stolle C, Thébault E, Thomson AWP, Tøffner-Clausen L, Velímský J, Vigneron P, Visser PN (2013) The Swarm Satellite Constellation Application and Research Facility (SCARF) and Swarm data products. Earth Planets Space 65:1. https://doi.org/10.5047/eps.2013.07.001

Onovughe E (2018) Usage of RC index as a good representation for characterising rapid variation signals in geomagnetic field studies. Sun Geosphere 13(1):77-87. https://doi.org/10.31401/SunGeo.2018.01.11

Pavón-Carrasco FJ, De Santis A (2016) The South Atlantic Anomaly: the key for a possible geomagnetic reversal. Front Earth Sci 4:40. https://doi.org/10. 3389/feart.2016.00040

Schaefer RK, Paxton LJ, Selby C, Ogorzalek B, Romeo G, Wolven B, Hsieh S-Y (2016) Observation and modeling of the South Atlantic Anomaly in low Earth orbit using photometric instrument data. Space Weather 14(5):330-342. https://doi.org/10.1002/20165W001371

Shure L, Parker RL, Backus GE (1982) Harmonic splines for geomagnetic modelling. Phys Earth Planet Inter 28:215-229. https://doi.org/10.1016/ 0031-9201(82)90003-6

Tarduno J, Watkeys M, Huffman T et al (2015) Antiquity of the South Atlantic Anomaly and evidence for top-down control on the geodynamo. Nat Commun 6:7865. https://doi.org/10.1038/ncomms8865

Terra-Nova F, Amit H, Hartmann GA, Trindade RIF, Pinheiro KJ (2017) Relating the South Atlantic Anomaly and geomagnetic flux patches. Phys Earth Planet Inter 266:39-53. https://doi.org/10.1016/j.pepi.2017.03.002

\section{Publisher's Note}

Springer Nature remains neutral with regard to jurisdictional claims in published maps and institutional affiliations.

\section{Submit your manuscript to a SpringerOpen ${ }^{\circ}$ journal and benefit from:}

- Convenient online submission

- Rigorous peer review

- Open access: articles freely available online

- High visibility within the field

- Retaining the copyright to your article

Submit your next manuscript at $>$ springeropen.com 